\title{
A Rare Complication of Low-Molecular-Weight Heparin Therapy: Bladder Hematoma
}

\author{
Düşük Molekül Ağırlıklı Heparin Tedavisinin Nadir Komplikasyonu: Mesane \\ Hematomu
}

Birdal Güllüpınar

Department of Emergency, Mersin Toros State Hospital, Mersin, Turkey

\section{ABSTRACT}

Introduction: Low-molecular-weight heparin is one of the most preferred agents used in the prevention and treatment of thromboembolic disorders.

Case Report: An 85-year-old female patient was admitted for 3 days with ongoing and growing vaginal bleeding. Bladder hematoma and postrenal acute renal failure, rare complications of low-molecular-weight heparins, are presented in this case.

Conclusion: Patients who have complaints about vaginal bleeding or hematuria should be questioned about a detailed history and the use of low-molecular-weight heparin. Lowmolecular-weight heparin in rare cases may lead to bleeding, and postrenal acute renal failure should be kept in mind.

Keywords: Low-molecular-weight heparin, bladder hematoma, acute renal failure

Received: 09.09.2013 Accepted: 24.12.2013

\section{ÖZET}

Giriş: Düşük molekül ağılıklı heparinler, tromboembolik hastalıkların tedavisi ve önlenmesinde kullanılan ilk tercih edilen ajanlardan biridir.

Olgu Sunumu: 85 yaşında bayan hasta 3 gündür olan ve son gün giderek artan vaginal kanama şikâyeti ile başvurdu. Düşük molekül ağırlıklı heparinlerin nadir bir komplikasyonu olan mesane hematomu ve sonrasında gelişen postrenal akut böbrek yetmezliği olgusunu sunduk.

Sonuç: Vaginal kanama veya hematüri şikayetiyle başvuran hastalara ayrıntılı anamnez sorgulaması yapılmalı ve düşük molekül ağırlıklı heparin kullanımı sorgulanmalıdır. Düşük molekül ağırlıklı heparinler nadir de olsa kanamalara ve postrenal akut böbrek yetmezliğine neden olabileceği akılda tutulmalıdır.

Anahtar Kelimeler: Düşük molekül ağırlıklı heparinler, mesane hematomu, akut böbrek yetmezliği

Geliş Tarihi: 09.09.2013 Kabul Tarihi: 24.12.2013

\section{Giriş}

Düşük molekül ağırlıklı heparinler (DMAH) tromboembolik hastalıkların tedavisi ve önlenmesinde kullanılan ilk tercih edilen ajanlardan biridir. Fraksiyone olmayan heparinler kadar etkili ve güvenli olmaları nedeniyle DMAH'lerin acil servislerde kullanım sıklığı artmaktadır (1). DMAH laboratuvar takibi gerektirmemesi ve hastane yatışı olmadan uygulanabilirliği nedeniyle fraksiyone olmayan heparinlere göre tercih edilir (2). DMAH fraksiyone olmayan heparinlere major kanama komplikasyonları, ölüm oranı ve tromboembolik nüks açısından üstün olduğu bulunmuştur $(3,4)$. Klinisyenler heparin tedavisi alan hastalarda trombositopeni ve tromboz komplikasyonlarına karşı dikkatli olmalıdırlar. Bu yazımızda DMAH'lerin nadir bir komplikasyonu olan mesane hematomu ve sonrasında gelişen postrenal akut böbrek yetmezliği olgusunu sunduk.

\section{Olgu Sunumu}

85 yaşında bayan hasta 3 gündür olan ve son gün giderek artan vaginal kanama şikâyeti ile başvurdu. Özgeçmişinde hipertansiyon, Alzheimer hastalığı, sağ kalça ve sağ omuz protez öyküsü (10 yıl önce), myomektomi ve sol overektomi öyküsü (5 yı önce) ve bir ay önce osteoporoza bağlı sekizinci torakal vertebra kompresyon kırığına bağlı operasyon öyküsü mevcuttu. 
Düzenli olarak amlodipin-valsartan 5-160 mg/gün, rivastigmin 6 mg/gün, ketiapin 25 mg/gün ve derin ven trombozu profilaksisi nedeniyle enoksaparin sodyum 60 mg/gün kullanıyordu. Sistolik/ diastolik kan basıncı 96/59 mmHg, nabız 75/dk, solunum sayısı $16 / d k$, ateş $36,1^{\circ} \mathrm{C}$ oda havasında oksijen satürasyonu \%92 idi. Genel durum iyi, bilinç açık, koopere, oryente olan hastanın fizik muayenesinde spekulum ile vagende eski kan görülmesi haricinde tüm diğer sistem muayeneleri olağandı. Labaratuvar tetkikleri glukoz: 109 mg/dL (80-115 mg/dL), BUN: 29 mg/dL (9,8-20,1 mg/ $\mathrm{dL})$, kreatinin: $3,7 \mathrm{mg} / \mathrm{dL}(0,6-1,3 \mathrm{mg} / \mathrm{dL})$, sodyum: $120 \mathrm{mmol} / \mathrm{L}$ (136-145 mmol/L), potasyum: 2,9 mmol/L (3,5-5,1 mmol/L), beyaz kan hücresi: 5,4 U/L (4-10,3 U/L), Hb: 8,9 g/dL (13,5-17,5 g/dL), Htc:

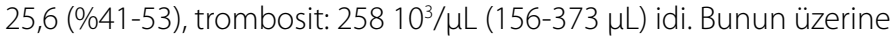
pelvik ultrasonografi (USG) istendi. USG'de; mesane sağ posterior duvarına bitişik superiordan inferiora doğru uzanım gösteren, 10x45×25 mm boyutunda, duvardan ayrı ızlenim veren ve içerisinde vaskuler kodlanma bulunmayan, hiper ve hipoekoik alanları bulunan, üreter orifislerini kapatan keskin sınırlı bir alan izlendi. Foley sonda takıldı ve yaklaşık 800 cc makroskopik hematürik geleni oldu. İlk planda mesane içi hematom lehine değerlendirildi (Şekil 1). Enoksaparin kullanımına bağlı mesane hematomu ve postrenal akut böbrek yetmezliği düşünüldü. Enoksaparin tedavisi kesildi ve herhangi bir başka antikoagulan ajan başlanmadı. Hasta üroloji servisine yatırıldı ve intravenöz hidrasyon tedavisi yapılan hastanın kreatinin değerleri düştü. Üroloji servisine yatırılan hasta, üçüncü günde şifa ile taburcu edildi. Taburculuk sonrası tekrar antikoagulan tedavi başlanmadı.

\section{Tartışma}

Günümüzde ölüm nedenlerinin başında trombotik hastalıklar gelmektedir. Bu hastalıkların profilaksisi ve tedavisinde antikoagulan ilaçlar; warfarin, standart heparin (fraksiyone olmayan heparin), düşük molekül ağırlıklı heparinler kullanılmaktadır.

DMAH, klasik heparinin kimyasal veya enzimatik depolimerizasyon sonucu elde edilen kısa heparin polimerleridir. DMAH, glikozaminoglikan yapısında bileşikler olup etkilerini Faktör Xa ve trombini inhibe ederek gösterirler (5). DMAH; biyoyararlanımı yüksek, yarı ömrü uzun olup subkütan, intravenöz veya intraarteriyel olarak verilebilir. Uzun yarılanma süresi nedeniyle DMAH kullanımı son derece pratik olup renal yetmezlik hariç laboratuar testine gerek duymadan günde bir veya iki kez kullanılabilir (6). Trombositler üzerinde daha az inhibitör etkisi olduğundan, damar duvarı ve trombositler arası etkileşimi daha az etkilediğinden dolayı standart fraksiyone olmayan heparine oranla daha az kanamaya neden olur (7).

Enoksaparin profilaksisi sonucunda komplikasyon oranları genel olarak \%0-6 arasında değişmektedir $(8,9)$. Hemoraji, enjeksiyon yerinde ekimoz, lokalize veya genel alerjik reaksiyonlar, trombositopeni, nadiren, enjeksiyon yerinde ciddi döküntülü reaksiyonlar, osteoporoz riski ve karaciğer enzimlerinde artış görülebilir (10).

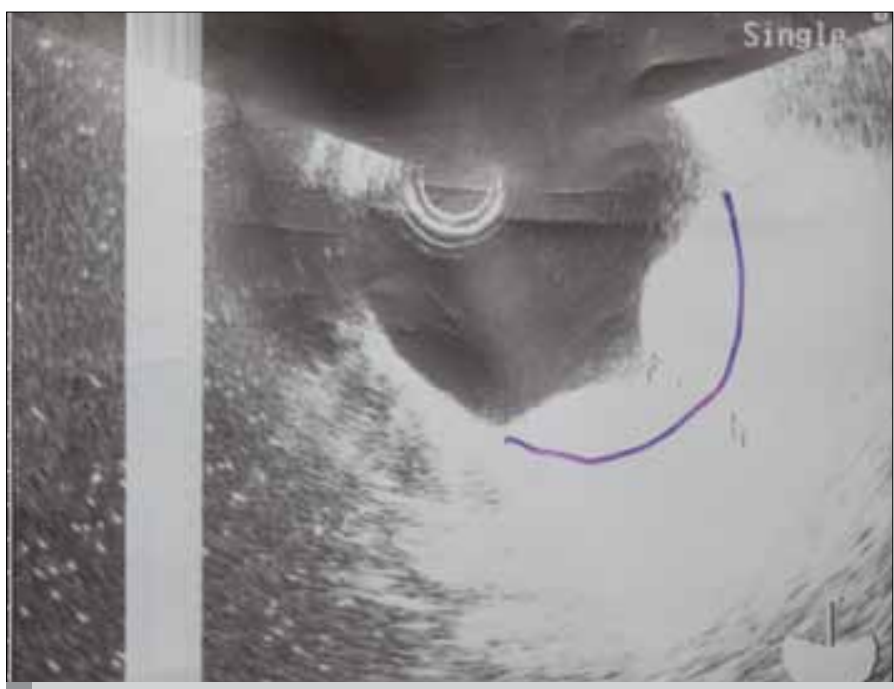

Şekil 1. Mesane hematomu

DMAH, fraksiyone olmayan heparine göre daha az kanama ve trombositopeni görülür, uzun süreli kullanımda osteoporoz görülmez. Heparinle ilişkili trombositopeni, DMAH tedavisinde yüksek morbidite ve mortalitesi olan ciddi bir komplikasyondur. Çok nadirde olsa retroperitoneal ve intrakraniyal kanama gibi majör hemorajiler bildirilmiştir. Bu olgulardan bazıları ölümle sonuçlanmıştır. Bizim olgumuzda da nadir görülen bir durum olan mesane hematomuna bağlı postrenal yetmezlik tablosu gözlenmektedir. Bu olgu, literatür taramamızda dünyada tanımlanan birinci olgu olması nedeniyle önemlidir.

Mesane hematomunun tanısında direkt grafi, USG, bilgisayarlı tomografi (BT) veya manyetik rezonans görüntüleme kullanılır. USG; noninvaziv ve hızı olması, doğruya yakın bilgi vermesi nedeniyle ilk tercih olmalıdır. BT ise, hematomun yerleşimini, boyutunu ve yayılımını saptamada USG'den daha üstündür. Hastanın tanı ve ayırıcı tanı açııından BT çekilmesi gerekirdi. Ancak hastanın böbrek fonksiyon testleri bozuk olduğundan kontrastlı BT çekilmemiştir.

DMAH ile tedavi edilen hastalarda komplikasyonlar genellikle hafif derecede olup kısa süreli tedavilerle komplikasyonlar giderilebilmektedir.

Hastamızda travma ve mesaneye cerrahi girişim gibi mesane hematomu yapabilecek diğer nedenler bulunmamaktadır. Bu nedenle oluşan mesane hematomu DMAH bağlı geliştiği düşünüldü.

\section{Sonuç}

Vaginal kanama veya hematüri şikayetiyle başvuran hastalara ayrıntılı anamnez sorgulaması yapılmalı ve DMAH kullanımı sorgulanmalıdır. DMAH nadir de olsa kanamalara ve postrenal akut böbrek yetmezliğine neden olabileceği akılda tutulmalıdır.

Informed Consent: Written informed consent was obtained from patient who participated in this case. 
Peer-review: Externally peer-reviewed.

Conflict of Interest: The authors declared no conflict of interest.

Financial Disclosure: The authors declared that this study has received no financial support.

Hasta Onamı: Yazılı hasta onamı bu olguya katılan hastadan alınmıştır.

Hakem Değerlendirmesi: Dış bağımsız.

Çıkar Çatışması: Yazarlar çıkar çatışması bildirmemişlerdir.

Finansal Destek: Yazarlar bu çalışma için finansal destek almadıklarını beyan etmişlerdir.

\section{Kaynaklar}

1. Gould MK, Dembitzer AD, Doyle RL, Hastie TJ, Garber AM. Low-molecularweight heparins compared with unfractionated heparin for treatment of acute deep venous thrombosis. A metaanalysis of randomized, controlled trials. Ann Intern Med 1999; 130: 800-9. [CrossRef]

2. Weitz Jl. Low-molecular-weight heparins. N Engl J Med 1997; 337: 688-98. [CrossRef]

3. Lensing AW, Prins MH, Davidson BL, Hirsh J. Treatment of deep venous thrombosis with low-molecular-weight heparins. A meta-analysis. Arch Intern Med 1995; 155: 601-7. [CrossRef]
4. Siragusa S, Cosmi B, Piovella F, Hirsh J, Ginsberg JS. Low-molecular weight heparins and unfractionated heparin in the treatment of patients with acute venous thromboembolism: results of a metaanalysis. Am J Med 1996; 100: 269-77. [CrossRef]

5. The Columbus Investigators. Low-molecular-weight heparin in the treatment of patients with venous thromboembolism. N Eng J Med 1997; 337: 657-62. [CrossRef]

6. Spinler SA, Nawarskas JJ. Low-molecular weight heparins for acute coronary syndromes. Ann Pharmacother 1998; 32: 103-10. [CrossRef]

7. Ji H, Li SP, Cheng X, Cheng HR, Ng TB, Li P, Li NS. Antithrombotic effects of low-molecular-weight heparin calcium (LMWH-Ca) in experimental models. Gen Pharmocol 1999; 33: 207-11. [CrossRef]

8. Menzin J, Richner R, Huse D, Colditz GA, Oster G. Prevention of deep-vein thrombosis following total hip replacement surgery with enoxaparin versus unfractionated heparin: a pharmacoeconomic evaluation. Ann Pharmacother 1994; 28: 271-5.

9. Deep K, Jigajinni MV, McLean AN, Fraser MH. Prophylaxis of thromboembolism in spinal injuries-results of enoxaparin used in 276 patients. Spinal Cord 2001; 39: 88-91. [CrossRef]

10. Cardiovascular Disease Educational and Research Trust; Cyprus Cardiovascular Disease Educational and Research Trust; European Venous Forum; International Surgical Thrombosis Forum; International Union of Angiology; Union Internationale de Phlébologie. Prevention and treatment of venous thromboembolism-International Consensus Statement (ICS). Guidelines according to scientific evidence. Int Angiol 2006; 25: 101-61. 